\title{
The way they see it: an evaluation of the Arts Across the Curriculum project
}

\author{
Abstract \\ This paper reports on an evaluation to interrogate the efficacy of a Scottish Government \\ sponsored initiative to introduce an arts-infused education model to primary (elementary) and \\ secondary (high) schools. \\ Arts Across the Curriculum (AAC) was a three-year pilot project, with ambitious aims. The aims \\ included aspirations to increase pupils' achievement and motivation to learn; to develop the \\ skills of teachers to work collaboratively and creatively; to encourage links between different \\ areas of learning and thus erode subject barriers. In addition, the project sought to improve the \\ ethos of the school and explore the efficacy of the expressive arts as a delivery mechanism across \\ the curriculum (FLaT, 2006).
}

Between April 2005 and December 2007, the evaluation team gathered data using a variety of instruments including surveys, structured observations, interviews and video diaries. This paper presents some of the findings from the evaluation and in particular it focuses on the artists' views of the efficacy of the project; in short we wanted to know how they 'saw it'.

It should be noted that the research team that evaluated the initiative had no say in the design of the AAC project. 


\section{AAC : the way they see it ...}

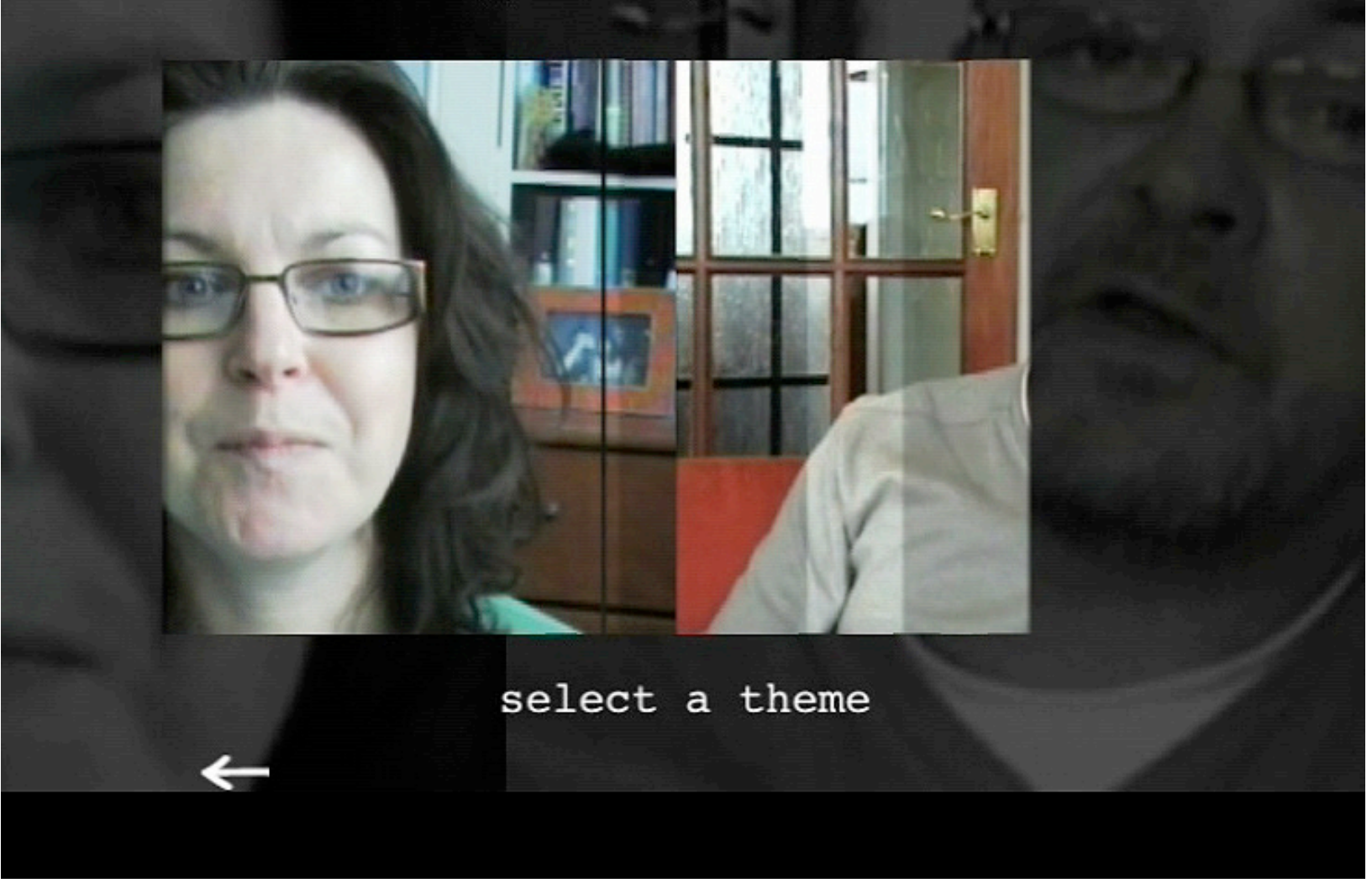

Figure One: Screen shot [DVD] select a theme

\section{Introduction}

The AAC project was sponsored by the former Scottish Executive's Future Learning and Teaching (FLaT, 2005) programme, the Scottish Arts Council, and seven local authorities (Scotland currently has 32 local authorities) in which the initiative was piloted and evaluated.

Within the aims of the AAC initiative, this paper focuses on one in particular: 'To support and develop the skills of teachers to work collaboratively and creatively'. The extent to which this aim was achieved is examined through the lens of a sample of the artists who worked with the teachers on the AAC project.

The ideas expressed in the project aims were drawn mainly from the Lakeview Education and Arts Partnership (LEAP, 2005) model and the lessons learned from the Arts Impacting 
Achievement (AIA, 2006) research project. These followed the Chicago Arts Partnerships in Education (CAPE) approach, commonly known in Scotland as the 'Chicago model':

CAPE advances the arts as a vital strategy for improving teaching and learning by increasing students' capacity for academic success, critical thinking and creativity (CAPE, 2004).

Founded in 1992, CAPE brings artists and teachers together to work collaboratively with the aim of developing innovative approaches to learning and teaching, infusing the arts into the school curriculum.

The LEAP initiative, which started in 1993 in Chicago, was formed with the central objective of increasing student achievement and engagement with learning by integrating the arts across the school curriculum. In the LEAP model, evolved from a 'drop out' prevention initiative, the arts are seen as a catalyst to increase achievement and motivation in students. LEAP and CAPE are not 'artist in residence' initiatives. Rather, they seek to have the artist and teacher plan and deliver core school subjects. In this model, the teacher and artist plan and teach together with the aim of promoting deeper understanding of school subjects. The Scottish model closely followed the Chicago projects.

It is important to emphasise that AAC was quite different from previous 'artist in education' initiatives in which artists brought skills and experiences into the classroom to enhance and complement the teacher's ability to make the arts more accessible to young people, or to promote engagement with particular arts disciplines. The AAC project set out to do something much more ambitious, promoting the notion of developing the skills of teachers to 'work collaboratively and creatively', encouraging links between different areas of learning and exploring the efficacy of the arts as a 'delivery mechanism' across the curriculum. During the life of the AAC project 
some 50 teachers, 30 artists, 400 secondary pupils and 600 primary pupils were involved in the project. Central to the AAC project, was the idea that the arts could enhance delivery of curriculum content - an 'arts-infused' model of education. For both teacher and artist this was a very new experience. The Scottish Arts Council's Cultural Co-ordinators (individuals with responsibility for promoting the arts in education), located in each local authority, paired artists and teachers or schools. Almost all of the artists had some experience of working in education, for example as an artist in residence, but none had been involved in a project with similar aims.

At the centre of both the Chicago model and the Scottish variants of it, was the 'Integrated Curricular Lesson' (ICL) derived from the LEAP project. The key purpose of the ICL was to enhance pupils' understanding of curriculum content through arts activity and, simultaneously, for teachers and pupils to gain greater insight into the arts. In a typical ICL the artist and teacher integrated their specialist knowledge by designing lessons to achieve this end. For example, in a secondary school the science teacher and a dance specialist taught together to enhance pupils' understanding of molecules. In a primary school a textile artist and sculptor working with class teachers taught different aspects of the topic of environmental studies (environmental studies in Scottish primary schools, includes history, science and geography). In the project there was significant variation in the pairings of school subject and arts discipline, including, for example mathematics and dance, English and video arts, science and drama, environmental studies and visual arts. The teachers and artists worked together to plan and implement ICLs. Whilst there was considerable difference in the ways in which the pairs approached the task, a typical model included the teacher identifying a part of the curriculum that was challenging for students to understand, difficult to teach or, sometimes, just tedious to teach. This became the focus for the ICL. For example, in the case of the science lesson, the teacher reported that it was difficult for 
the students to understand or 'visualise' molecules. The artist provided alternative ways of representing concepts, for instance through movement or mime.

In primary schools one project involved a drama specialist working with the teacher on a topic, for example 'World War Two' or 'The Victorians', in which the students were immersed in learning about the lifestyle and problems faced by people during that period. Activities included making props, scripting and role-play. In a secondary school, a theatre lighting director worked with the art and English department to study poetry and created a performance space in a disused area of the school. The entire process, lasting several months, was documented and the student readings of poetry were filmed.

Careful, collaborative planning and team teaching was the overall aim. The length of each series of ICLs varied enormously across the entire AAC project, but there were no 'one-off' interventions, the artist and teacher worked together typically for one day a week for four to six weeks. In general, the teachers were very complimentary about the pedagogical skills of the artists, none of whom were trained as teachers. The artists proved to be intuitively skilled at asking questions and promoting understanding, they also reported enjoying the planning process as well as the teaching.

However, as Eisner's research on the relationship between participation in the arts and academic achievement (Eisner, 1998; 2004) and the importance of ethos in education (Eisner, 1994) reminds us, effective learning depends on much more than careful planning or motivated teachers and pupils. Cropley argues that for creativity to be employed effectively in the classroom, teachers must create the right conditions for learners $(2001,135-153)$, and that they should do this by modifying their practice in certain ways including taking more 'risks' and 
allowing time for 'sensible errors' on the part of learners. The artists involved in this project worked with the teachers to find alternative ways of presenting and interpreting curriculum content and this involved embracing a range of strategies often quite new to the teachers. According to Robinson (2001, 129-131), creative processes and the opportunity of 'finding your medium', offer great potential for enhancing self-esteem. Since teachers and learners are often unfamiliar with these processes, there may be scope for enriching the learning process through arts-infused teaching. In this study, the research team investigated the extent to which experience of AAC influenced learners' and teachers' inclination to adopt and fully engage in more creative approaches to learning, by asking the artists to reflect on their experiences of AAC.

The literature, mainly from the United States (Catterall \& Waldorf, 1999; Eames, Benton, Sharp \& Kendall, 2006) and England (Cochrane \& Cockett, 2007; CP, 2006; Ofsted, 2006), suggests that there may very well be benefits to learners, teachers and artists of arts in education programmes. However, the question of transfer of knowledge remains a topic of some debate (Catterall, 2002; Winner \& Hetland, 2000). In this study we asked the artists about the benefits of infusing arts across the curriculum, and the conditions that might be optimal for realising any benefits.

\section{Evaluation aims}

The AAC project team, which was coordinated by the Scottish Arts Council, designed the initiative and set out the aims of the project. In the context of arts interventions in Scotland, the AAC project was a highly significant initiative - ambitious in its aims and relatively expensive; it was important that a thorough evaluation was undertaken. When commissioning the authors to 
carry out the 30-month evaluation, the following aims were agreed with the Scottish Government (then the Scottish Executive):

1. Describe the extent to which the six key aims of the Arts Across the Curriculum Project (AACP) have been met

2. Identify strengths and any gaps in the training and support available to teachers and artists involved in the Arts Across the Curriculum Project in the participating schools

3. Assess the overall impact of the Arts Across the Curriculum project on teachers, artists and pupils in the participating schools (including any gender differences in relation to outcomes) and in the local communities and arts organisations

4. Explore how the expressive arts can be used as a vehicle for carrying current school curriculum knowledge and for achieving broader educational targets

5. Establish conditions that support effective implementation and embedding of the Arts Across the Curriculum Project.

The data resulting from the video interviews is the key focus here. It is beyond the scope of this paper to report on all of the results of such an extensive study. However, the full findings are available in our final report (Soden, Seagraves, \& Coutts, 2008). 


\section{Outline of research design}

The evaluation was carried out over two phases of data collection which involved surveys and interviews with key participants (pupils, teachers and artists); six artists provided rich data through the compilation of video diaries. In addition, there was an in-depth study in three schools that involved semi-participant observation including an extended exploration of teachers' and artists' understandings of the project aims and how these might be implemented effectively. For instance, during semi-participant observation in one school, the researcher participated in lesson planning discussions with a science teacher and a drama worker about a series of lessons that culminated in students writing and performing a play that explored their understanding of what happens when electricity flows through circuits.

\section{Interviews}

The purpose of the interviews and video diaries was to gain more detailed or 'fine-grain' data than might be gathered using questionnaires, although the questionnaires did have open questions, which allowed for comment. All artists and teachers taking part in the project were sent questionnaires at each phase of the study. In addition all of the artists were offered the opportunity to make a video diary in order to complement and enrich data from the questionnaires with more personal reflections. Design of data collection tools was particularly influenced by the evidence from the literature on the conditions associated with effective artseducation partnerships and perceived outcomes for pupils, teachers and artists (ACE, 2004; Harland et al., 2000; Harland et al., 2005; Ofsted, 2006; SAC, 2008; SEED, 1999, 2000). The questionnaires, interviews and video diary schedule posed questions about the early stages of the project, the process of implementation and reflection on apparent outcomes for participants.

Semi-structured formats were used for all of the interviews. The questions were framed around 
the aims of both the AAC project and our evaluation. The major questions were asked in the same way with each interviewee, thus setting a first level of themes for the analysis. However, the semi-structured approach allowed both interviewers and interviewees the freedom to pursue interesting lines of inquiry developing out of the interviewees' own experiences of the project and to change the order of the questions, if necessary.

A mixture of individual and group interviews was held at two points, near the start of the intervention and again towards the end of the project. Teachers were interviewed both individually and in groups. Group interviews were held when this arrangement suited the school in terms of time commitment and availability of staff. At both stages, artists were interviewed by telephone. This was primarily a logistical decision as the artists were located widely across the country and had commitments other than AAC, which meant that arranging face-to-face interviews was extremely complex.

\section{Video diaries}

An early decision was taken to use video cameras as part of the battery of data collection instruments in the research. The provision of video cameras was an economical but more importantly, flexible method of data collection that, the researchers hoped, artists would be comfortable with. Artists who elected to use a video camera were not interviewed by telephone.

The interview data were analysed by comparing and contrasting themes that emerged from the interview. In reality these themes were very closely related to the original questions asked. The video data were analysed by transcribing the text and colour coding themes emerging from the responses. 


\section{AAC : the way they see it ...}

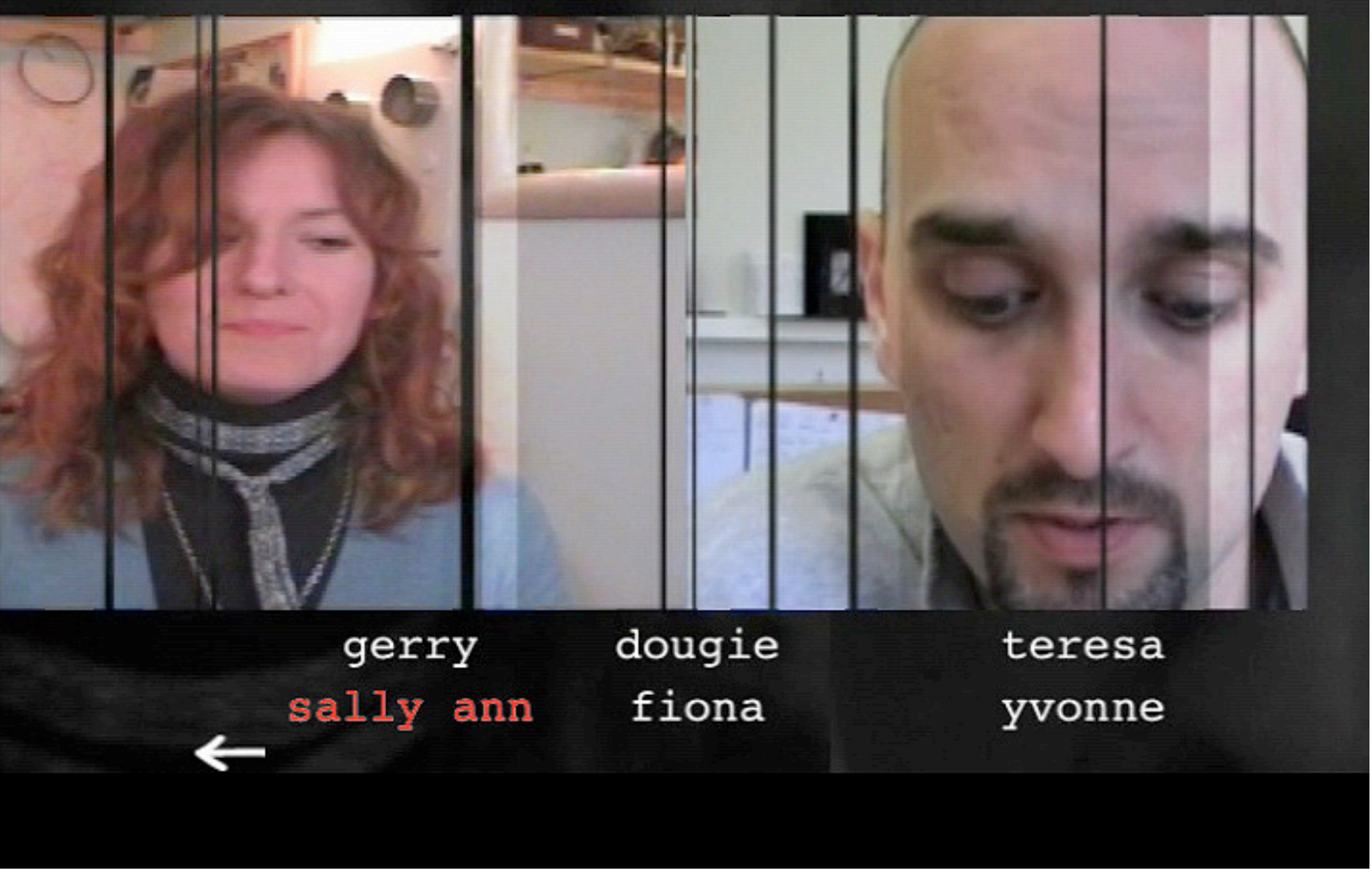

Figure Two : Screen shot [DVD] option to browse by artist

Semi-structured interviews or 'talking heads' on camera have been employed successfully by Coutts (Coutts, 2000; Coutts \& Dougall, 2005; Coutts, Mitchell, \& Austin, 2004) to explore a range of issues in the arts and education. The artists were provided with some simple advice on setting up the camera, lighting and sound requirements and a semi-structured 'shooting schedule' with prompts designed by the research team and agreed with the participants. This approach allowed the respondent a degree of autonomy and flexibility. There was an open invitation to all artists to make a video diary, eight took up the invitation and six completed the task by submitting videotapes. The artists also had the option of inviting the teachers they worked with to contribute to the video commentary; interestingly, none of the artists took up this option.

The participants comprised a range of arts disciplines: three drama specialists, one dance 
specialist and two visual artists. Each respondent was given the same set of instructions, a JVC GR-D290EK digital video camera and a 60-minute digital videotape. In addition, a time frame for completion was negotiated with each person, to take into account the type of ICL and the length of time that the artist would be working on the project in the school. Typically, the artist had the video equipment for between four and ten weeks, sufficient time for the artist to work in the school(s) and reflect on the experience. Participants were asked to reflect on three key dimensions of their involvement in AAC: planning and development, implementation and evaluation.

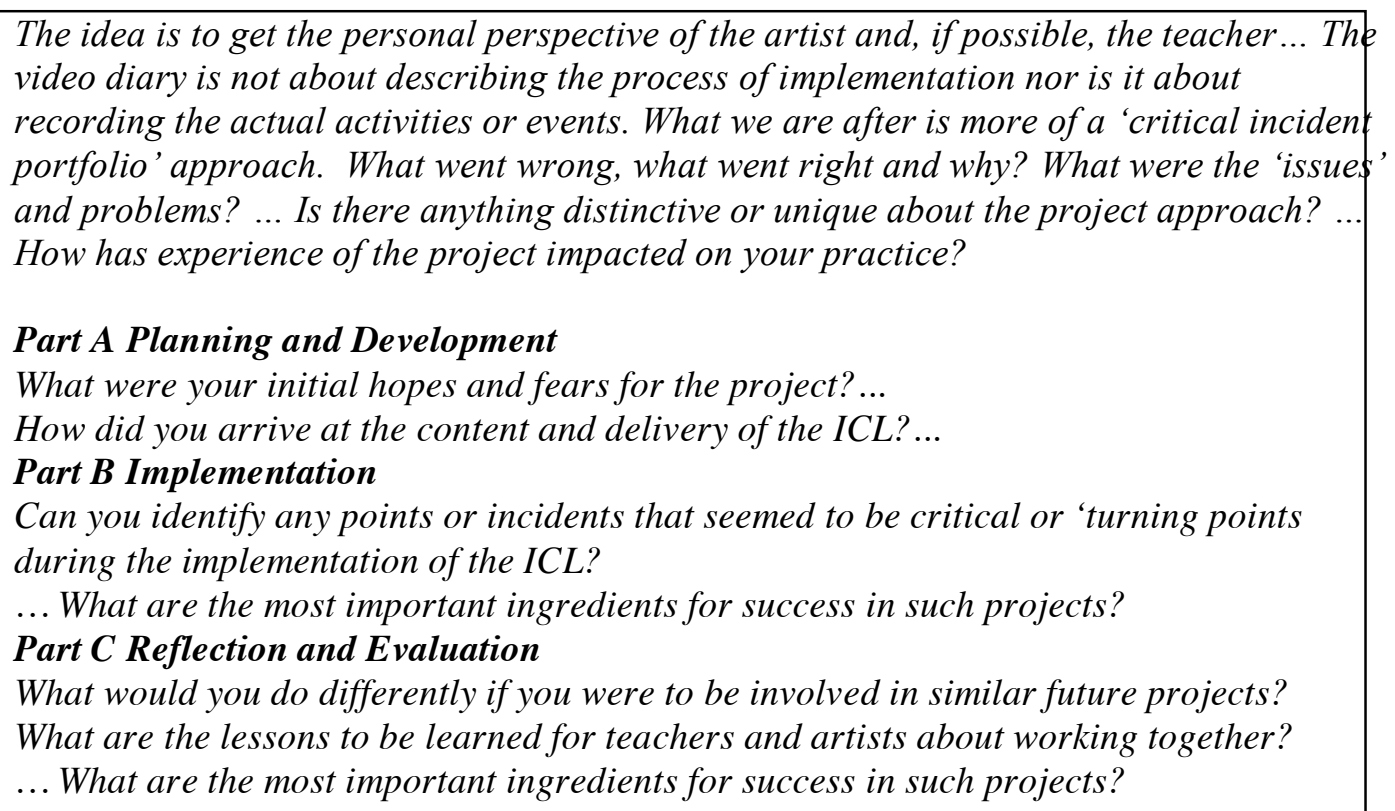

Figure Three: Extracts from the instructions to artists

Questions in the instructions to artists used the same broad categories and set of prompts as those contained in the schedule used for artists who agreed to be interviewed by telephone.

It should be noted that the term 'video diary' proved somewhat problematic and may have been a 
factor that caused some artists to 'opt out' of the opportunity to participate in this dimension of the research, believing it to mean that they had to record their entire interaction with school students and teachers, which was not the intention.

\section{Analysis}

The tapes were coded using a subjective colour coding system. Transcripts of video diaries were inductively analysed following the procedures recommended by Berg (2004). The videotapes were transcribed by research assistants; themes were extracted from the text, colour-coded, and 'common threads' were identified. The themes were then grouped together to form general categories related to the questions the artists were asked. Nine broad categories of themes emerged. Electronic folders were created into which a research assistant, skilled in video editing, placed video clips illustrating the themes. The clips were then compiled into a DVD, which became an appendix to the final report. 


Motivation to participate in the project
Perceptions of relationship between arts and education
Initial hopes and fears of the initiative
Problems encountered
Positive outcomes (pupils)
Positive outcomes (artists)
Key benefits (pupils)
Ingredients for success
Future recommendations

\section{Figure Four: Colour coding for themes}

\section{What did they say?}

\section{Planning and Development}

The concept of artists and teachers working to deliver aspects of the curriculum was new to most of the artists, but they all had previous experience of working in education. Taken together, the data suggest that teachers and artists collaborated very well together. The AAC project managers had provided exemplar 'planning sheets' that were met with mixed responses, some used them but many did not, one artist reported that he found the planning sheets 'a killer to developing ideas'. According to the artists, success depended on setting realistic goals for a series of ICLs and careful analysis of the concepts learners were to grasp. A key factor was the artist's ability to help pupils to represent challenging curricular concepts through artistic activities. Artists' initial hopes and fears reflected their concern to do the best job possible, whilst recognising the limitations of the project in terms of its duration. One drama specialist, who worked with several schools, both primary and secondary, in a range of subjects, reflected: 
... my initial fears are that we will get so tied up with the delivery that we will forget that the project still requires a lot of development, in order to be really effective in working for us here in Scotland. In short, we need to put our stamp on it.

Another theatre director, who worked on a primary school environmental studies topic, expressed similar concerns:

... I think I was hopeful that it would be a really bold model for taking education forward, to find a way to make sure that kids are creatively engaged in their own education as much as in the classes...

Time to meet and plan together was an issue that artists felt was extremely important - 'you need time to develop a relationship with the teacher' reported one visual artist.

One musician who had worked with a secondary school English department, commented on fears about matching the art with the curricular aims

'The main fear is that you were trying to put two things into one in terms of the art form and subject area and I think one of them would always have to be subservient, I don't see how they could co-exist happily together.

Other fears included not having sufficient resources (space, equipment or materials) and the problem of fitting arts activities into the school timetable. This was reported to be more problematic in secondary than primary schools.

\section{Implementation}

Evidence of teachers and artists developing ideas jointly was more marked in the second than in the first year of the project, possibly because it takes time to develop understanding of the sophisticated idea of integrating art with curricular content and using different methodologies to enhance learning. The evidence shows that, for the most part, the artists and teachers were 
adapting the Chicago model in sensible, productive ways to fit curricula in Scottish schools. Implementation was not without its problems however and the match of arts discipline to curricular content emerged as a key issue for some artists. One drama specialist who had worked with a primary school in the areas of language and 'personal and social development' reflected on the need to 'play to the strengths' of both the art form and school subject:

I think we latched on to a subject that wasn't really suitable for our art form. We started to look at smoking in particular and in my mind, smoking ... maybe for another artist it might have been much more interesting, but I don't think that it engaged the children, I think the children knew the right answers to give us and I think they were bored by it actually, I don't think we inspired them and I think it was because to get drama to really work you have to get to the core of a dilemma, of a real question, a question that doesn't have an answer, ... and smoking has an answer ... you know what you want them to learn and it just felt like it wasn't really working.

The AAC project had a wide variety of arts discipline and curriculum content pairings most of which worked well according to the artists in the video diary sample, but some were sceptical:

I'm not sure how I could use my skills to bring mathematics alive... if they are looking at fractions, to get them to pretend to be a king dividing up his kingdom into thirds and halves... I just don't think it feels like it's using arts to teach.

Throughout the project, the arts activities were being used to help pupils learn other knowledge and this significantly differentiates AAC activities from most other Scottish initiatives that have introduced artists into schools. The vast majority of teachers reported that it took longer to cover the curriculum content, but for most this situation was manageable. However, the extra time invested led to deeper understanding of the topic and was often recovered subsequently through not having to re-explain concepts at a later stage. One of the AAC project's central aims of deploying the arts as 'delivery mechanisms' was certainly taken on board by the artists, but not 
without some critical reflection. A jewellery artist who worked in a secondary school with students in a science (chemistry) project reported:

I think as an artist... it strikes me that you are secondary to young people's learning. I mean at the end of the day you are there to support the curriculum, you are there to try and smuggle in of course whatever creativity you can ... I don't think my teacher was firm enough in saying to me "look this is what the learning outcomes are that I want to be achieved by the end" it was almost too flexible.

The artists had clearly thought very carefully about 'ingredients for success', most referred to the need for teamwork, collaboration and communication between artist and teacher. In addition, they commented on the need for open-mindedness, commitment and recognition of the underlying principles of AAC among teachers. A dance specialist who had worked with a secondary school's English and science departments over a period of almost two years, talked about the need for communication:

The most important ingredient for success in such projects is communication basically. We need the teachers to talk to us and we need the teachers to be right there next to us. It's not about us coming and taking their session and the teachers going and having a rest. It's about the teachers and the artists working together... 


\section{AAC : the way they see it ...}

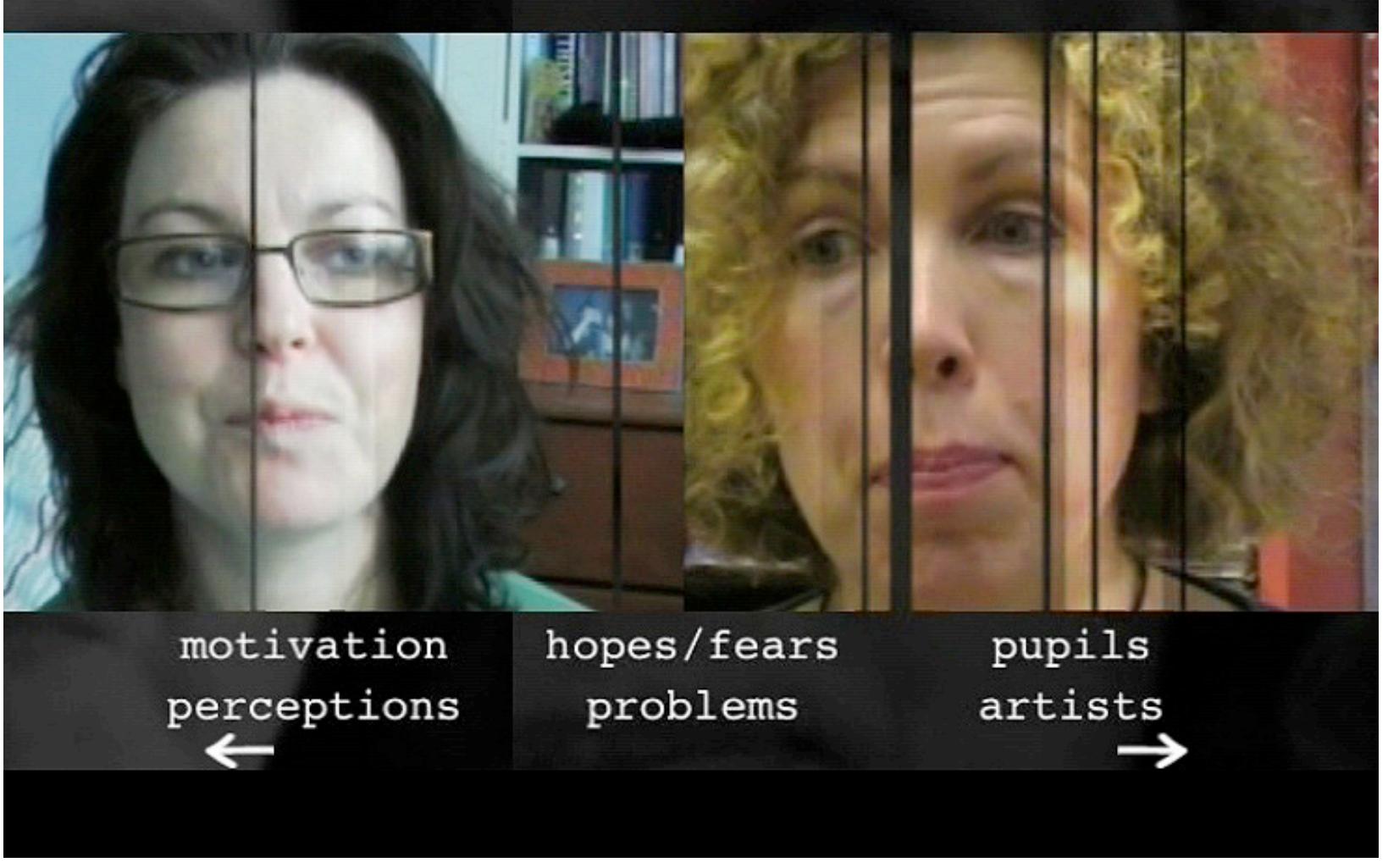

Figure Five: Screen shot [DVD] browse by theme

\section{Reflection and Evaluation}

In summary, the artists were very positive about the intervention; all had experience of working in education, but no specific knowledge of teaching curriculum content through the arts. None of the artists reported noticing any gender difference in response or performance, or the project having much impact on his or her arts practice. They were relatively knowledgeable about the LEAP model, but unaware of other models. One musician commented that the arts are “extremely important academically and not just a peripheral thing". He did however recognise the risks, commenting that $\mathrm{AAC}$ should not be seen as a way of justifying the arts by suggesting that you can use them to promote learning in 'more important' subjects. The artists who took part in the video diary part of the evaluation were articulate and reflective and, as many teachers 
commented during interviews, had excellent pedagogic skills and were keen to share their experiences and offer advice for future projects:

To teachers and artists embarking on such a project, I would advise them to talk regularly, listen to each other, observe each other in their working environment and finally remember why they went into their chosen profession in the first place.

Evidence from the questionnaires suggests that teachers' perceptions of AAC were also generally positive, with the initiative considered to be effective in making learning more accessible to all pupils (particularly those at the lower end of the ability range), taking a holistic approach to pupil development and connecting classroom learning to real life. Whilst the perceived effects on academic attainment were ambiguous according to responses, AAC was seen to have a strong positive impact on psychosocial characteristics such as confidence and team working. Limitations of the model are, however, evident and these include constraints caused by the time consuming nature of preparing and delivering ICLs and the consequent conflict between developing creativity among pupils while also achieving learning outcomes. According to this sample, important 'lessons to be learned' for future projects include support from the head teacher and school management, integration and promotion of AAC across the whole school, availability of appropriate space and allocation of adequate time for project planning and delivery of lessons. A drama specialist who worked across four secondary and two primary schools with subjects ranging from Modern Studies and Learning Support in secondary schools to the topic of 'The Victorians' in primary schools offered this advice:

Go into it with your eyes open, working in drama I truly believe I can teach anything using drama ... I might not have thought that before, I definitely think that now.

Issues for consideration in any future such initiatives could be summarised as follows: 
- Time for planning and teacher commitment to the project is vital.

- The relationship between the teacher and the artist is crucial - according to one artist, they must "gel”.

- Artists and teachers must be open to flexible ways of working.

- Teachers need to take time to understand the basics of the art discipline and artists need to take time to understand the curriculum.

\section{AAC : the way they see it ...}
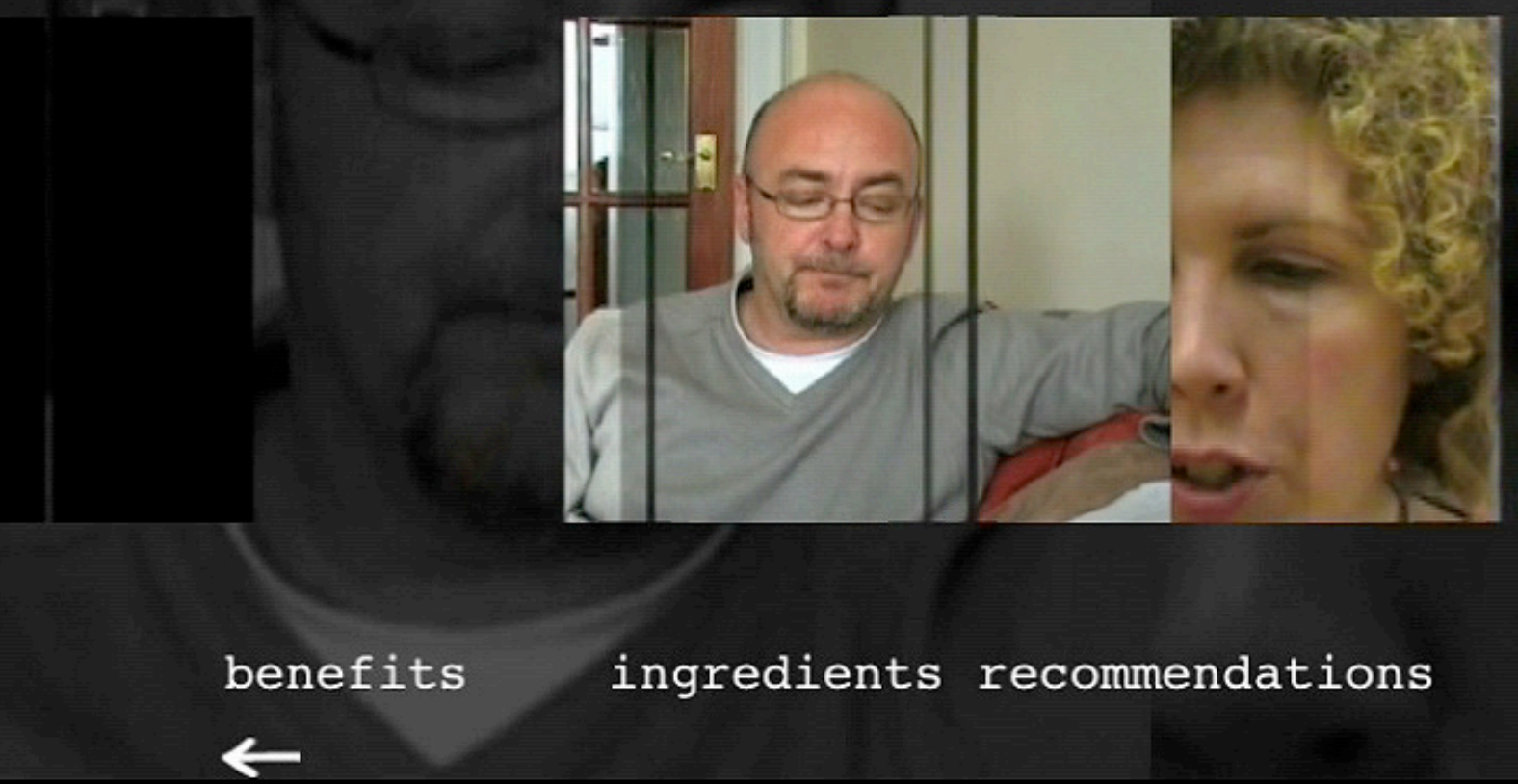

ingredients recommendations

Figure Six: Screen shot [DVD] possible benefits, ingredients for success and recommendations for the future.

\section{Concluding comment}

The results are in line with findings from other studies (Doherty \& Harland, 2001; Upitis \& Smithrim, 2003). Doherty and Harland report factors associated with successful implementation 
include:

- Effective communication.

- Effective targeting of the creative activities (matching the skills available to pupils' abilities, resources, time constraints).

- Strong leadership and the active involvement of the school Senior Management Team .

- Extension of activities beyond a narrow curriculum base or a location identified with the arts.

These are also found, and explored in greater depth by Harland et al. (2000; 2005). It is clear that when teachers and artists felt AAC was working well, they thought it worked really well. There are some issues to be resolved however, and much further research needs to be carried into such areas as the relationship between the design of the intervention(s) and implementation; the need for training and support for both artists and teachers and the crucial dimension of the support of managers in schools. Perhaps it is worth concluding with a comment from one artist's video diary:

I believe there needs to be more arts training for teachers and more teacher training for some artists going in to school but again I've held this belief long before Arts Across the Curriculum began. Maybe this project will be a catalyst for change in skills training.

Notes: $A A C$ : The Way They See It [DVD] is available from: www.strath.ac.uk/degas.

The authors would like to thank the artists who made video tapes for this part of the evaluation, 
colleagues at the University of Strathclyde, Dr Jane Mackay for content analysis and Fiona Stewart for video editing and DVD authoring. 


\section{References}

ACE. (2004) The impact of the arts: some research evidence. London: Arts Council England.

AIA. (2006). Arts Impacting Achievement. Available from URL: http://artsimpactingachievement.org/ (Accessed 7 March, 2009).

Berg, B. (2004). Qualitative Research Methods for the Social Sciences (5th ed.). Boston, MA: Allyn and Bacon.

CAPE. (2004). Chicago Arts Partnership in Education. Available from URL: http://www.capeweb.org/ (Accessed 7 March 2009).

Catterall, J., S , \& Waldorf, L. (1999). Chicago Arts Partnerships in Education: Summary Evaluation In B. Fiske (Ed.), Champions of Change: the Impact of the Arts on Learning. Washington DC: Council of Chief State School Officers.

Catterall, J., S. (2002). The Arts and the Transfer of Learning [Electronic Version]. Critical Links: Learning in the Arts and Student Academic and Social Development, 151-157. Available from URL: http://www.aep-arts.org/publications/info.htm?publication_id=10 (Accessed 6 March 2009).

Cochrane, P., \& Cockett, M. (2007). Building a Creative School: a Dynamic Approach to School Development. Stoke on Trent: Trentham Books.

Coutts, G. (2000). Using Multimedia to Introduce Young People to Public art in Glasgow. International Journal of Art and Design Education, Vol. 19, No. 3, pp. 262 - 271.

Coutts, G., \& Dougall, P. (2005). Drawing in Perspective: Scottish Art and Design Teachers Discuss Drawing. The International Journal of Art \& Design Education, Vol. 24, No. 2 , pp. 138-148.

Coutts, G., Mitchell, L., \& Austin, J., K. (2004). Motivating trainee social workers: an artsinfused model. Paper presented at the First international Colloquium on Arts Education Motivation. Ljubljana.

CP. (2006). Creative Partnerships. Available from URL: http://www.creative-partnerships.com (Accessed 6 March 2009).

Cropley, A. J. (2001). Creativity in Education and Learning: A Guide for Teachers and Educators London: Kogan Page.

Doherty, P., \& Harland, J. (2001). Partnerships for Creativity: An Evaluation of Implementation Slough: National Foundation for Educational Research (NFER).

Eames, A., Benton, T., Sharp, C., \& Kendall, L. (2006). The impact of creative partnerships on the attainment of young people: Final report. Slough: National Foundation for Educational Research (NFER).

Eisner, E., W. (1994). Ethos in education. In Perspectives: a series of occasional papers on values and education. Dundee: Scottish Council on the Curriculum.

Eisner, E., W. (1998). Does experience in the Arts Boost Academic Achievement? Art Education, Vol. 51, No.1, pp.7-15.

Eisner, E., W. (2004). What can education learn from the arts about the practice of education? [Electronic Version]. International Journal of Education and the Arts 5. Available from URL: http://www.ijea.org/v5n4/index.html (Accessed 7 March 2009).

FLaT. (2005). About Future Learning and Teaching (FLaT). Available from URL: http://www.flatprojects.org.uk/aboutflat.asp (Accessed 7 March 2009). 
FLaT. (2006). FLaT-Projects Spanning Education-Arts Across the Curriculum. Available from URL: http://www.flatprojects.org.uk/projects/a_authareas/artsacrossthecurriculum.asp (Accessed 7 March 2009)

Harland J, Kinder K, Lord, P., Stott A, Schagen, I., \& Haynes, J. (2000). Arts Education in Secondary Schools: Effects and Effectiveness. Slough: National Foundation for Educational Research (NFER).

Harland, J., Lord, P., Stott, A., Kinder, K., Lamont, E., \& Ashworth, M. (2005). The artseducation interface: a mutual learning triangle? . Slough: National Foundation for Educational Research (NFER).

LEAP. (2005). Lakeview Education and Arts Partnership. Available from URL: http://www.neiu.edu/ ctc/leap/menu.html (Accessed 7 March 2009).

Ofsted. (2006). Creative Partnerships: initiative and impact (No. 2517): HMI.

Robinson, K. (2001). Out of Our Minds: Learning to be Creative. Oxford: Capstone.

SAC. (2008). Scottish Arts Council - Priorities for Education. Available from URL: http://www.scottisharts.org.uk/1/artsinscotland/education/priorities.aspx (Accessed 7 March 2009).

SEED. (1999). Creating Our Future...Minding Our Past, A National Cultural Strategy. Edinburgh: Scottish Office Education Department.

SEED. (2000). The Education (National Priorities) (Scotland) Order 2000. Available from URL: http://www.opsi.gov.uk/legislation/scotland/ssi2000/20000443.htm. (Accessed 7 March 2009).

Soden, R., Seagraves, L., \& Coutts, G. (2008). Evaluation of the Arts Across the Curriculum Project [Electronic Version]. Available from URL: http://www.scottisharts.org.uk/1/information/publications/1005453.aspx (Accessed 7 March 2009).

Upitis, R., \& Smithrim, K. (2003). Learning Through the Arts: National Assessment 1999-2002: Final Report to the Royal Conservatory of Music Ontario. Ontario: Queen's University.

Winner, E., \& Hetland, L. (2000). The arts and academic achievement: What the evidence shows Journal of Aesthetic Education. Vol. 34, Nos. 3 \& 4. 